\title{
Fighting for our Rights. Perceived Gains from Transforming the Curriculum through a Narrative of Activism
}

\author{
${ }^{1}$ Paty Paliokosta, ${ }^{2}$ Theresa Nash \\ ${ }^{1}$ Kingston University and $S t^{2}$ George's, University of London
}

\begin{abstract}
This paper will analyse the gains from 'Fighting for our Rights' project (2016-2018) focusing on the use of real-life experiences in $H E$ teaching and beyond. This was a Heritage Lottery funded project that entailed collecting and sharing stories from people involved in the Disability Rights Movement (DRM) from 1960s to 1990s within Kingston in order to inspire future generations of care professionals and teachers in working with people with disabilities. It was the outcome of a collaboration between two university departments (Schools of Nursing and Education), a centre for independent living (CIL), two social enterprises, oral history consultants, and a local school for children with severe learning difficulties. It captured 30 years of local history (1960-1990) in a permanent digital record of the DRM and produced a school resource pack to enhance public engagement and inform university and school curricula.
\end{abstract}

\section{Introduction}

Between 1960s and 1990s disabled people from Kingston were at the forefront of the Disability Rights Movement in the UK and were instrumental in the closure of large institutions and the creation of independent living, the formation of user-led organisations, the introduction of direct payments and the Disability Discrimination Act (1995). At the time, the social model of disability was coming into action, moving the focus to the environment rather than the impairment [1]. As part of this ongoing activism, a user-led group was formed in Kingston in 1967 (eventually becoming KCIL in 2001) that campaigned and lobbied for equal rights and acceptance. It was pertinent to preserve this historical material, in various formats, before it was lost as a source of knowledge and inspiration for the community and future generations. The timing for preserving this historical material was extremely relevant, as currently the independent living scheme has been under attack and several activists were approaching the end of their life.

Through their inclusion in the project, two university departments aimed to improve awareness, knowledge and understanding of student nurses and student teachers about disability and inclusion in their developing professionalism in HE and beyond. This would be facilitated by learning about local disabled people's activism, by finding out about independent living and by embedding information in the given HE modules through collaborative work and co-production, while building relationships with people with disabilities and the wider community. According to Joshi and Moore [28], coproduction requires major changes in the roles and responsibilities of stakeholders, whereas Vargo and Lusch [29] also emphasized the importance of enhancing the role of beneficiaries in the service coproduction [17].

The project produced the following outputs for a range of beneficiaries:

a. The development of a permanent digital record of the DRM to inspire future generations of professionals and people with disabilities;

b. A Drama production with local children;

c. Displays at Kingston Museum, Kingston Heritage Centre in the Guildhall and 4 local libraries;

d. A resource Pack for Educators (KS2) that included 13 cross-curricular lesson-plans inspired by the life-narratives based on the project transcripts made by student teachers.

This paper will discuss the perceived gains in higher education and its interaction with the community through the notion of relational learning while developing a narrative of activism.

\section{Exploring the relevant evolving history context; the Education perspective}

In order to understand the significance of the project, it is important to locate DRM in the context of the discourses and legislative frameworks operating in education within that time-frame (19601990). In order to approach contemporary ideological movements or political conversations and their impact upon society or education, it is pertinent to understand their history [14].

The disability rights movement (DRM) in the UK pushed for significant changes in attitudes and structures for 'disability' within and across institutions and society and intended to achieve equality and rights for those with disabilities, fighting 'institutionalisation' and 'exclusion' in the workplace, society and education [14], [30].

In terms of legislation, the movement towards integration and later inclusion in England had already 
started with the Warnock Report in 1978 that radically changed the conceptualisation of special educational needs. Warnock regarded the education system of the time to be focusing exclusively on the negative and deficient dimension of the person. She urged that 'its place should be a more positive approach based upon the concept of SEN' (DES, 1978 p.37). Prior to this report, the categories of disability existing were not only stigmatising and degrading for the person, but they also provided no information on the provision required [27]. This demonstrated a shift from policies rooted in a medical model to those with a more educational dimension.

Particularly in education, Warnock's report was followed by the 1981 Education Act which abolished the term 'handicap'. The actual idea of special educational needs (SEN) was introduced as were 'statements' of SEN that followed with the Warnock report in 1978. These represent the system of provision that lasted until 2014. It sought for an 'integrative'- which later became known as 'inclusive' - approach, based on common educational goals for all children regardless of their abilities or disabilities: namely independence, enjoyment, and understanding (Select Committee on Education and Skills, 2006). There was a gradual move from an individualised or 'deficit model' of disability (Dyson, 1990) to a focus on the interaction between impairment and environment [1] and later to a social model of disability in the political discourse. Full inclusion was achieved in the Education Reform Act (DfES 1988), which gave all pupils entitlement to access the National Curriculum. The significant changes taking place in the UK in terms of SEN and inclusion policies since 1978 added to a gradual effort to ensure all children's right to participation in England, the right and entitlement of children to be educated in mainstream classes along with their peers irrespective of differences and background continued gaining great momentum in the 1990s, alongside activism for independent living.

\subsection{Why is this project relevant?}

Following the developments above, in terms of legislation, policy and initiatives, things were looking brighter for inclusion in the 1990s and more so from the perspective of education. The first fundamental UK policy promoted by the New Labour's Green Paper 'Excellence for All Children' led to a revised inclusive curriculum. It outlined the government's commitment to high quality education for pupils with Special Educational Needs within the context of inclusion [20].

The 'reasonable adjustments' duty had also already drawn on a wide set of policy frameworks and legislation to protect, amongst other duties, children and families from discrimination. It became statutory in 2007 and plethora of supportive material, a large part of which created by Disability Equality in Education (DEE) was made available to support settings on the implementation of what could be seen as a far more social orientated model of disability. The Equality Act (HMRC, 2010) provided a 'modern, single legal framework, and a clearer, more streamlined law that will be more effective at tackling disadvantage and discrimination'.

However, despite a strong narrative pro inclusion since 1997, inclusive policies were not developed in a straightforward manner, as it often happens [5], the process of translation and re-contextualisation involved in the realisation or enactment of policy in specific national and local settings was dependent on experience and local sensitivities. Similar were the difficulties and discrepancies in the context of the implementation of the independent living scheme [12] despite efforts of local CILs. Warnock also took a new look on the inclusion debate [21], stating that inclusion in schools had gone too far.

\subsubsection{Why is this relevant to our developing} professionals: Evidence suggests Healthcare students continued limited exposure to this client group during training results in limited confidence and skills to work with people with learning disabilities; this appears to directly result in poorer attitudes and unclear idea of their role within healthcare teams to advocate for this group.

At the same time, more children with Special Educational Needs and disabilities (including mental health) are excluded. Children with moderate, severe and profound learning disabilities are increasingly educated in special schools and there is an expansion in the SEN sector in England, as more children are living with moderate and profound learning disabilities, leading to an expansion of school sector and resulting in more teachers entering special education but without specialist education to support their role.

On top of this, the current social care system has been in many ways incapable of delivering the right to independent living set out in article 19 of the UN Convention on the Rights of Persons with Disabilities [18], at the same time, the notion of inclusion has been debated (DFE, 2014), despite the protection of Equality Act (EHRC, 2010). Professor Mike Oliver, the pioneer of the social model of disability, who very recently passed away, left us with a legacy to keep considering 'how disabled people's historical and contemporary experiences are captured, articulated and used as a way to bring about emancipation [17].

Building on Oliver's utterance, underpinning legislation is pertinent, but cultures and discourses are also fundamental for the development of inclusive attitudes; when it comes to educational institutions, teachers' positive attitudes are seen as key factors to implementing inclusive education [4], [6], [10] but 
these do not operate in a vacuum. They are part of a wider ecosystem with several dimensions.

\subsection{Conceptualising this history and turning engagement with local history into a vehicle for change}

In order to achieve this on a dual level (educate our students who will then educate their students or involve patients and community members) we drew on critical pedagogy [2] as a fundamental means in the practice of freedom [24] in schooling and higher education; advocacy around engaged pedagogy, grounded in feminist and civil rights education [26] has also been central in the narratives, their interpretation and transformation into a teaching tool that would raise awareness of eduacators and children on the DRM of the past and its relevance to the present. This theoretical stance enables the recognition of oral history, as subjective, but powerful source of history, valuable to understanding our social and cultural past.

By connecting the individual stories of the disability rights movement directly with young people with learning disabilities today, the students were able to better understand the history of their own profession, and to place themselves within it. For some, this was a prompt to look at their own context with a critical eye, and to question if progress was still being made. An evaluation of gains took place amongst the key stakeholders involved in the Fighting for our Rights project; data was collected from partners by an independent evaluative interviewer and from student teachers and nurses through a questionnaire distributed by the project manager.

Semi-structured interviews was guided by a set of questions tailored to suit the role of the partner within the project. The data was transcribed, collated and analysed, drawing out key themes and individual points to illustrate the range of responses across the partners. It is important to clarify that this stakeholder evaluation was not intended to provide an independent evaluation of the experience of the project informants.

\section{Perspectives on perceived gains.}

\subsection{Main themes identified:}

a) Engaging with lived experiences

I. making heritage relevant today

II. a bridge between past and present

III. bringing the theoretical to life

b) Sharing a powerful, personal perspective

c) Highlighting relevant connections

d) Breaking down stereotypes and changing perceptions

e) Developing relationships and understanding
Analysis and examples follow.

3.1.1. Engaging with lived experiences: Particularly in education, drawing on the historical information presented above, there has been a reversal, in the sector towards a more institutionalised, medical model. The teaching students could see the relevance of what goes on nowadays in policy for special needs and inclusion in relation to what was happening between the ' 60 s and ' $90 \mathrm{~s}$. But the use of this project helped the tutors take it even further back. That helped with being able to see disabled people's rights within a continuum, and to be able to reflect on what is going on at the moment. Initially some students said, "Oh, why are we learning about the past? Surely now we've got improvements." But first of all, it's about activists' history and we need to honour it if we're going to learn anything about how to do things. Such projects can be particularly relevant in the current climate, as they could raise the profile of important issues and make a worthwhile difference. From a student nurses' perspective, it was about 'doing a history, also think about how it might link today to health.' Students were, thus able to relate to the material and actively reflect in the context of relational learning.

This project was the 'final bit of the puzzle that enabled us to really think that we're doing something worthwhile, because people aren't listening still, and people just don't get what it means to have multiple complex disabilities with vision, hearing loss, speech, physical, mental, emotional, social... ultra-complex disabilities. It's how all these things intertwine.' (Nursing lecturer).

This project connected people with reality of other peoples' lives, past and present. There were entwined elements of gathering and sharing oral histories, and of developing work with and for schools. Student nurses, student teachers, disability rights activists and SEN pupils were all participants, working alongside the stakeholder partners. The stakeholders shared their thoughts on the many ways in which engaging with these lived experiences had had a positive impact on those involved, and also identified some of the challenges it brought. This real-life project gave students new opportunities to test their theoretical knowledge in real life situations. For the nursing students, it was said to be beneficial to be spending time learning in different environments outside of the usual clinical environment, and to be working in a different way (in this case buddy acting). It was felt that this gave them a much deeper understanding of the issues involved. The nursing lecturer felt that for the students to work alongside the pupils in the school environment, 'going through that experience of trying to share the story and going through that experience of oppression and empowerment, was incredibly powerful.' Whilst learning in this way has been done for some time in Australia, Canada and the USA, is 
not common practice for student nurses in the UK. This revolutionised and transformed the student nurses' experience [22], [25], who normally meet patients 'in a hospital on a busy ward, they're never allowed to sit with them for two hours and hear their life story, so they don't really get the story.' (Nursing lecturer)

Experiential learning, originally discussed by John Dewey, recognises the need to learn within 'real world' situations [9], [8], [19]. The education lecturer recognised that an amazing learning experience was created by the project, because several of the theories and strategies previously or currently taught could be put into a real-life context. Using real stories in a relational space [7] can enhance students' relational abilty, where personal meaning is found. This can present with difficulties; one student had become upset during the first day of working with the transcripts on the project and relating to the people's stories. Whilst difficult at the time, this was a useful experience for the student that was supported by a negotiated narrative in a safe environment and this eventually played a valuable part in their professional education. 'I enjoyed learning about our wider community, learning about how the education system had an everlasting effect on individuals due to their differences to what was classed as a social norm at the time. It allowed me to compare and contrast what ethos I want to carry in my classroom and how to address this topic in schools without shining a negative light upon it' (student teacher).

\subsubsection{Sharing a powerful, personal perspective:} The narrative aspect of this project enabled listening to others and sharing personal stories. This was seen to be rooted in an approach which gave people the space to share their own personal perspective. 'You just allow people to be who they are. You've got to give them that space to understand that actually, they are part of the story and they have a story to tell' (project's story teller).

The individual oral histories were particularly powerful because of their simplicity and immediacy of people whose early memories were of oppression and lack of agency, and those pivotal moments when they were able to take control and engage in a form of political activism. Part of the power of sharing these stories, is that they allow others to understand these moments within the broader context of the experience and the abilities of each individual at that moment in time.

'The richness of the stories that came through the oral transcripts was very powerful. Very real. There was a quality where people had started off trying to assert their rights to have some sort of life or control over parts of their life. It wasn't about "I need to fight for something else." It's simply, "I want some food at the time that I come back," or "Why is it I can't get on a bus?" or "Why is it, as a medical professional, you're not allowing me to tell you how I feel when you push a needle in me, or hear what I'm saying?". These were the 'why' questions that a number of these amazing people were asking, and they asked them from when they were able to do so.' (Nursing tutor).

One education student said: 'I feel that what we were able to produce by the end changed due to this exercise as we were able to really embed ourselves in the stories' recognising the interaction of self with the stories and the community.

3.1.3. Highlighting relevant connections to the profession: The oral histories powerfully connected people to individuals who were living and working locally, making strong, relevant connections. For the participating school teacher, using the authentic oral histories as a starting point, gave the project 'substance.' He valued the strong local connections, and felt that, for him and a few of his students, this 'added a real value to it, and certainly helped the students to identify what the project was all about.' The raw data from the informants seemed to automatically be a resource itself open to interpretation.

In the context of sharing this data with Higher Education students as part of their Pedagogy module, it was important to emphasise that this was 'a civic engagement project that actually dealt with real life people who were amongst us'. One of the project participants was a lecturer at the participating university and the widow of a former KCIL serviceuser. This was a unique opportunity to support students with operating around sensitive issues and use appropriate language. This provided a very real context where a code of conduct to students was introduced, which linked closely to the module's learning objectives and to Teachers' Standards. 'Being part of it was enhancing their ability to show professionalism and professional conduct around sensitive topics. It was preparing them for practice' (Education lecturer).

3.1.4. Breaking down stereotypes and changing perceptions: Engaging with the lived experiences of others was seen to be a powerful tool in challenging stereotypes. The curriculum could be enhanced through introducing real, lived experiences to new areas of the teaching and nursing courses. True stories were incorporated into teaching materials by using oral histories instead of fictional scenarios to support understanding of social construction in relation to disability. 'Taking part in this project allowed me to have a whole different perspective on disability. Learning all about how these individuals are only disabled when society places a barrier in front of them. But also learning about how it just takes one person to make a change that will have a domino effect on so many people.' 


\section{Initial impact}

The intended impact for $\mathrm{HE}$ was to improve awareness, knowledge and understanding of nurses and teachers about disability and inclusion in their developing professionalism, as student teachers and student nurses in $\mathrm{HE}$ and beyond. In the context of this study, this would be facilitated by learning about the role of disabled people's involvement in activism, by finding out about independent living and by embedding information in the given HE modules through collaborative work and co-production, while building relationships with people with disabilities and the wider community. Although, certain types of knowledge such as factual or disciplinary propositional knowledge may be relevant for transmission approaches [11], there can be a static element to them, that does not enable the transference of new 'knowledge' to other contexts [23]. This type of knowledge was described by Eraut as situated or 'process know-how' knowledge viewed as essential to professional practice.

Learning, through participation has been argued as core to developing such 'situated' knowledge [20], where students can actively participate with disciplinary discourse [3], [9], [17]. A positive ripple effect has already been seen by stakeholders, reaching beyond the scope of the original project and, within the university, other programmes have been adopting and incorporating this type of project. It is anticipated that the project will have an even broader reach, as international students graduate and return to their country of origin, taking with them, this empowering approach to nursing and education.

The school resource for educators is available on line and will be piloted in local schools, so this impact at classroom and school level is yet to be evaluated through small scale studies. The indicative lesson plans are cross-referenced and address several topics relating to inclusion and disability from the perspective of different National Curriculum subjects, based on themes stemming from the oral history interview narratives. The material follows a mastery approach, whereby children will have the opportunity to understand real-life experiences to make learning relevant and not abstract, connecting with commitments relating to the UN Convention of the Rights of Persons with Disabilities, the Children and Families Act 2014 and the Equality Act (HMRC, 2010), the topic is approached through different National Curriculum subjects in order for children to approach it in depth and from multiple perspectives. School staff will be invited to make relevant choices of subjects, personalise and use them, according to need and context.

All the stories can be adapted by the university faculty curriculum and real people, who created these narratives, are willing to come into teach on our courses. Currently two nursing modules in Year 2 [long-term conditions] and Year 3 [complexities of service provision] wish to use these stories as part of their curriculum with an aim to create multidisciplinary input with the School of Education. The resource for Educators can also support lesson planning for nursing academics. The potential is fairly broad.

\section{Summary: From Heritage Learning to Activist Professionalism}

The project made heritage relevant today in many ways. It built a bridge between the individual stories of the disability rights movement and young people with complex disabilities today at a quite controversial policy climate as explained above. It enabled students to look back at their own profession with a critical eye, and to place themselves, and contemporary practice within the arc of history.

The gains of this project strongly align with the transformational ideology of education defined by Jack Mezirow [13], [15] and expressed within Sachs [4] activist professionalism. In that education can be 'emancipatory' [24] and hence transformative where learners can recognize and question their assumptions or 'frame of reference' and hence change how they 'think, feel and act in the world' [16]. Whilst some learning can be instrumental (factual), learning is not solely dependent on students' solitary action in response to instruction, but is deeply relational in nature. It is posited that this is a transferable experience that could further enhance the teaching and learning practices across the university and shape students' developing professional identity. Stakeholders indeed identified this as a formative, eye-opening project, which had given them a very positive experience, both personally and professionally. People felt that their understanding of others had been developed, their relationships strengthened and their approach to their own work fortified.

\section{References}

[1] Ainscow, M. (1998) Would it work in theory? Arguments for practitioner researcher and theorising in the special needs field, in: C. Clark, A. Dyson \& A. Millward (Eds) Theorising special education. London, Routledge.

[2] Anderson, R. C. (2006) Teaching (with) Disability: Pedagogies of Lived Experience, Review of Education, Pedagogy, and Cultural Studies, 28:3-4, 367-379.

[3] Ashwin,P., Boud, D., Coate, K., Hallett, F., Keane, E., Krause, K-L., Leibowitz, B., Maclaren, I., McArthut, J., McCune, V., and Tooher, M. (2015) Reflective Teaching in Higher Education. London Bloomsbury.

[4] Avramidis, E. \& Norwich, B. (2002): Teachers' attitudes towards integration / inclusion: a review of the literature. In: 
European Journal of Special Needs Education, 17(2), 129147.

[5] Ball, S. J. (2000): 'Performativities and fabrication in the education economy: towards the performative society?' In: The Australian Educational Researcher, 27(2), 1-23.

[6] Batsiou, S., Bebetsos, E., Panteli, P., \& Antoniou, P. (2008): Attitudes and intention of Greek and Cypriot primary education teachers towards teaching pupils with special educational needs in mainstream schools. In: International Journal of Inclusive Education, 12, 201-19.

[7] Bergum, V. (2003) 'Ralional Pedagogy. Embodiment, improvisation and independence', Nursing Philosohy, 4, $121-128$

[8] Biesta,G.J.J.(2013) The Beautiful Risk of Education. London: Paradigm Publishers

[9] Brockbank, A. and McGill, I. (2007) Facilitating Reflective Learning in Higher Education. Second Edition. Society for Research into Higher Education and Open University Pres

[10] de Boer, A. Pijl, S. J., \& Minnaert, A. (2011): Regular primary schoolteachers' attitudes towards inclusive education: a review of the literature, International Journal of Inclusive Education, 15:3, 331-353

[11] Eraut, M.(1992) Chapter7. Developing the Knowledge Base: A Process Perspective on Professional Education. in Barnett, R.(ed)(1992) Learning to Effect . The Society for Research into Higher Education and Open University Press, pp.98-118.

[12] Evans (2003) The Independent Living Movement in the UK, Independent Living Institute (ILI) https://www.indepe ndentliving.org/docs6/evans2003.html) (10 March 2019)

[13] Fanghanel, J. (2012) Being and Academic. London: Routledge Press.

[14] Gibson. S. (2015) When rights are not enough: What is? Moving towards new pedagogy for inclusive education within UK universities, International Journal of Inclusive Education, 19:8, 875-886

[15] Illeris, K. (2009) Chapter One: A Comprehensive understanding of human learning in Illeris, K. (ed)(2009) Contemporary Theories of Learning . Learning theorists...in their own words. London: Routledge.

[16] Mezirow,J. (2009) Chapter 6. An Overview of Transformative Learning in Illeris,K.(ed) (2009) Contemporary Theories of Learning . Learning theorists...in their own words. London: Routledge

[17] Munirudheen A., Al-Maskari, A. and Kumudha, A (ND) Coproduction of Knowledge: A Literature, Review and Synthesis for a University Paradigm, Quality Approaches in Higher Education Vol. 6, No. (http://asq.org/edu/2015/03/socialresponsibility/coproducti on-of-knowledge-a-literature-review-and-synthesis-for-auniversity-paradigm.pdf) (10/1/19)
[18] Pring, J. (2019) Independent living in https://www.disabilitynewsservice.com/broken-promiseshave-shattered-hopes-of-right-to-independent-living-saysmorris/) (20/3/19)

[19] Sãlãvãstru, D. (2014) Experiential learning and the pedagogy of interrogation in the education of adults. Procedia-Social and Behavioural Sciences 142,pp.548-552

[20] Stamm, L. (2009) Civic Engagement in Higher Education: Concepts and Practices, Journal of College and Character, 10:4, DOI: 10.2202/1940-1639.1050

[21] Warnock, M. \& Norwich, B. (2010) edited by Lorella Terzi. Special Educational Needs: A new look. London: Continuum Books , 2010.

[22] Weimer, M.(2013) Learner-Centred Teaching. Five Key Changes to Practice. Second Edition. US:Jossey-Bass

[23] Hughes, S.J. \& Quinn, F.M. (2013). Quinn's principles and practices of nurse education. Nelson Thornes: Cheltenham.

[24] Freire, P., (1972), Pedagogy of the Oppressed. Harmondsworth: Penguin.

[25] McAllister, K. and Maguire, B. (2012), A design model: the Autism Spectrum Disorder Classroom Design Kit. British Journal of Special Education, 39: 201-208. doi:10.1111/1467-8578.12006.

[26] Hooks, B., (1994) Outlaw Culture: Resisting Representations New York: Routledge.

[27] Norwich, B., Kelly, N., (2005). Moderate learning difficulties and the future of inclusion. London: RoutlegeFalmer.

[28] Joshi, A., \& Moore, M. (2004) Institutionalised Coproduction: Unorthodox Public Service Delivery in Challenging Environments, The Journal of Development Studies, 40:4, 31-49, DOI: 10.1080/00220380410 001673184 .

[29] Vargo, S., Lusch, R., (2004). Evolving to a New Dominant Logic. Journal of Marketing. 68. 1-17. 10.1509/jmkg.68.1.1.24036.

[30] Abberley, P. (1987). The concept of oppression and the development of a social theory of disability. Disability, Handicap \& Society, 2(1), 5-19. https://doi.org/10.1080/ 02674648766780021

\section{Acknowledgments}

Acknowledgements go to the other members of the project team, Jen Kavanagh (PM), Gillian Butler, Eli Anderson, Neil Mears and Chris Hutchison, KCIL and to Catherine Mailhac for the independent data report that informed the data discussion. 
International Journal for Cross-Disciplinary Subjects in Education (IJCDSE), Volume 10, Issue 2, June 2019 